\title{
Mipu1 Inhibits Lipid Accumulation Through Down-Regulation of CD36 in RAW264.7 Cells
}

\author{
Shun-Lin Qu ${ }^{a}$ Wen-Jing Fana,b Chi Zhang ${ }^{a}$ Fang Guo Wen-Jun Pan ${ }^{a}$ Dan Han ${ }^{a}$ \\ Wei Lia Yu-Ning Zhu ${ }^{a}$ Zhi-Sheng Jiang ${ }^{a}$ \\ apost-doctoral Mobile Stations for Basic Medicine, Institute of Cardiovascular Disease and Key Lab for \\ Arteriosclerology of Hunan Province, University of South China, Hengyang City, ${ }^{\circ}$ The Second Affiliated \\ Hospital, University of South China, Hengyang City, China
}

\section{Key Words}

Mipu1 • Macrophages $\bullet$ Lipid accumulation $\bullet$ CD36 $\bullet$ oxLDL

\begin{abstract}
Background/Aims: Our recent data indicated that Mipu1 overexpression reduces lipid intake and CD36 expression of macrophages in the presence of oxLDL. However, the mechanism of Mipu1 inhibiting lipid accumulation in macrophages is not elucidated. Methods: Realtime quantitative polymerase chain reaction (PCR) and western blot analysis were used to detect expression of Mipu1 and CD36. The promoter activity of CD36 was studied using luciferase assays. Chromatin immunoprecipitation (ChIP) was used to show the recruitment of Mipu1 onto the CD36 promoter. High-performance liquid chromatography and Dil-labeled lipoprotein were used to detect cholesterol accumulation. Results: Here, we show that CD36 overexpression rescues oxLDL-induced cholesterol accumulation in RAW264.7-Mipu1 cells. Analysis of the mouse CD36 promoter revealed two potential Mipu1-response elements (MRE), one of which (from -237bp to -244bp, ACTTAC) was shown, using mutagenesis and deletion analysis, to be functional. Mipu1 was demonstrated to bind to CD36 promoter, and oxLDL treatment resulted in increases in their interaction as assessed by ChIP. Conclusions: It was demonstrated that Mipu1 inhibited the lipid accumulation of macrophages and it downregulated CD36 expression in the presence of oxLDL.
\end{abstract}

\section{Introduction}

The formation of macrophage-derived foam cells is considered to be the hallmark of atherosclerosis (AS), which is the leading cause of death and illness throughout most of

S.-L. Qu and W.-J. Fan are co-first authors.

Zhi-Sheng Jiang

KARGER 125
Institute of Cardiovascular Disease, Key Lab for Arteriosclerology of Hunan Province, University of South China, 28 West Changsheng Road, Hengyang 421001 Hunan (China) Tel. +867348281409, Fax +867348281279, E-Mail qushunlin78@126.com 
the world [1-3]. During atherosclerotic lesion development, the migration of circulating monocytes into the subendothelial arterial space and their differentiation into macrophages are considered to be the essential steps [4]. Scavenger receptors (SR) on macrophages have been proven to play a key role in the foam cell formation due to their ability to bind and internalize modified lipoproteins, a variety of proteins are involved in cholesterol accumulation [5-8]. Cluster of differentiation 36 (CD36), an 88-kDa transmembrane glycoprotein expressed in a wide variety of cell types, plays an important role in the uptake of oxLDL $[7,9,10]$, which is a well-known risk factor for AS, as the capacities of oxLDL intake and foam cell formation are both decreased significantly in CD36 $6^{--}$mice [11]. Inhibition of CD36 expression has been demonstrated to inhibit the development of AS [12-14]. Thus, further elucidating the mechanisms underlying the regulation of CD36 expression will be very important for the formation of novel therapeutic approaches to AS [15, 16].

Mipu1 (myocardial ischemic preconditioning up-regulated protein1), a new member of $\mathrm{KRAB} / \mathrm{C} 2 \mathrm{H} 2$ zinc-finger superfamily protein, has a KRAB domain and 14 C-terminal $\mathrm{C} 2 \mathrm{H} 2$ zinc fingers with an open reading frame of $1,827 \mathrm{bp}$ for encoding 608 amino acids [17, 18]. Like other $\mathrm{KRAB} / \mathrm{C} 2 \mathrm{H} 2$ zinc-finger proteins, Mipu1 is a DNA-binding protein and binds to the specific DNA sequence TGTCTTATCGAA, with CTTA as the core sequence, and Mipu1 acts as a transcriptional repressor, as determined by a reporter gene assay $[18,19]$. It has been identified that Mipul could reduce $\mathrm{H}_{2} \mathrm{O}_{2}$ - and TNF- $\alpha$ - induced H9c2 apoptosis, via repressing Fas and Bax expression [18, 20, 21]. What's more, we recently discovered that Mipu1 overexpression reduces lipid intake and CD36 expression of macrophages in the presence of oxLDL [22]. However, the mechanism of Mipu1 inhibiting lipid accumulation in macrophages has not been elucidated.

In this study, our results demonstrated that Mipu1 regulated CD36 expression and lipid uptake, and identified a functional Mipu1-response element (MRE) in the mouse CD36 promoter during oxLDL stimulation in RAW264.7 cells.

\section{Materials and Methods}

Cell culture and treatment

The RAW264.7 cells were obtained from the Type Culture Collection of the Chinese Academy of Sciences (Shanghai, China). RAW264.7 cells were cultured in DMEM (Gibco) supplemented with $100 \mathrm{U} / \mathrm{ml}$ penicillin and $100 \mu \mathrm{g} / \mathrm{ml}$ streptomycin and $10 \%$ fetal bovine serum at $37^{\circ} \mathrm{C}$ under $5 \% \mathrm{CO}_{2}$. RAW264.7 cells were treated with oxLDL at different concentrations and time intervals.

Generation of stably transfected RAW264.7-Mipu1 cells

Stably transfected RAW264.7-Mipu1 cells were employed as described previously [르. RAW264.7Mipu1 cells were transfected with mouse CD36 in pIRES plasmid (Clontech), and after transfection for 48 hours, cells were incubated with oxLDL at different concentrations and time intervals.

Quantitative real-time reverse transcription PCR (RT-PCR)

Total RNA was extracted using the TRIzol reagent (Invitrogen), and cDNA fragments were generated by reverse transcription using the Promega reagents. A total of $100 \mathrm{ng}$ of cDNA was used in the real-time PCR to measure Mipu1 mRNA expression, whereas $10 \mathrm{ng}$ of cDNA was used in the $\beta$-actin control PCR. The primer sequences used for the amplification were designed using the Primer 5.0 software and were evaluated using the Oligo 5.0 software. The primer sequences for CD36 were: forward 5'-GAACC TATTGAAGGCTTACATCC-3, reverse 5'-CCCA GTCACTTGT GTTTTGAAC-3'; for Mipu1: forward 5'GGAGGAATGGGAATGGCTGAGT 3', reverse 5'CCCATGGTGCTTTCCCTTTCTC 3'; for $\beta$-actin: forward 5'-TGGCCGGGACCTGAC AGACTA-3', reverse 5'- ATCTGAAGCTCGTC CTCTACCGG-3'. SYBR Green I fluorescence dye (Takara Biotechnology, Dalian, Japan) was used to bind specifically to the minor groove of double-stranded DNA. All reactions followed the typical sigmoidal reaction profile, and cycle threshold was used as a measurement of amplicon abundance as described previously [23]. 


\section{Cellular Physiology Cell Physiol Biochem 2015;37:879-889 \begin{tabular}{ll|l} 
and Biochemistry & $\begin{array}{l}\text { DOI: 10.1159/000430215 } \\
\text { Published online: September 18, } 2015\end{array}$ & $\begin{array}{l}\text { C 2015 S. Karger AG, Basel } \\
\text { www.karger.com/cpb }\end{array}$ \\
\hline
\end{tabular} \\ Qu et al.: Mipu1 Inhibits Lipid Accumulation}

Western blot analysis

Western blot was carried out with Mipu1 [24], CD36 and GAPDH (Cell Signaling Technology) antibody [25] according to a previous publication. Electrophoresis and immunoblotting were employed as described previously.

\section{Lipid uptake assay}

Two different methods were used to detect the uptake of lipids by macrophages. In the first assay, RAW264.7 cells were washed with PBS for three times after being treatment with oxLDL(The TBARS content was ranging from 5 to $15 \mathrm{nmol} \mathrm{MDA} / \mathrm{mg}$ cholesterol). Protein content was determined by BCA kit. Proteins were precipitated with $6 \%$ trichloroacetic acid, and neutral lipids were extracted with a mixture of hexane/isopropanol (v:v 4:1). The organic phase containing the lipids was collected in a vacuum freeze drying plant at $65^{\circ} \mathrm{C}$ and the residues were redissolved in $0.1 \mathrm{lL}$ mixture of isopropanol/n-heptane/ acetonitrile(v:v35:12:52). The mixture was centrifuged at $1500 \mathrm{rpm}$ for 5 minutes. Cholesterol ester content was analyzed by high-performance liquid chromatography (HPLC) [26] as described previously (http:// www.ncbi.nlm.nih.gov/pubmed/25141035). For the second method, oxLDL (v/v, 4:1) was labeled with 1,1'-dioctadecyl-3,3,3',3'-tetramethylin docarbocyaninet (Dil) overnight at $37^{\circ} \mathrm{C}$. Dil-oxLDL was incubated with RAW264.7 cells for 24 hours at $37^{\circ} \mathrm{C}$, then cells were washed three times with PBS, and then lysed in lysis buffer. The protein concentration was detected by BCA assay. Dil fluorescence was detected following at excitation at $520 \mathrm{~nm}$ and emission at $590 \mathrm{~nm}$ using a $590 \mathrm{~nm}$ cut-off filter (Gemini XS microplate fluorometer). A fluorescence standard curve was prepared by diluting 0, 1, 2, 4, 8, 16 and $32 \mu \mathrm{g}$ Dil-oxLDL in lysis buffer. Results were normalized to total cell protein concentration.

Plasmids and constructs

A 1500-bp fragment (pGL3-1143) ranging from position -1200 to+299 relative to the transcription start site of the mouse CD36 gene was amplified via PCR using the primers F-1200 (GCCGGTACCTAAGTAACTCGTTCAATATGA) and R+299 (5'- CGGTTCGAATATAGGTAGATCTGTAAATAACA -3') flanked by KpnI and HindIII restriction sites (restriction sites are in italic) as described before [25]. The amplicons were digested with KpnI and HindIII ligated into the promoterless luciferase reporter plasmid pGL3-Basic (Promega). Other deletion constructs were generated by PCR using the common reverse primer $\mathrm{R}+299$ and the following sense primers (restriction sites are in italic): for construct pGL3-600, 5'- GCCGGTACCTCAGCTAAATTAACAACAA AAAATGA -3'; for construct pGL3-230, 5'GCCGGTACCGAACATGGCCAAAA AAAAAAAAAAAAGACT $-3^{\prime}$. Mutant versions for specific binding sites were prepared by PCR using the common primer pGL3-1200 combined with the following forward primer, which carries a point mutation for MRE-Mut, $5^{\prime}$ - CCCATCCAGC AGCACAAGAGGCCAGAGAACCA - $3^{\prime}$, and the following reverse primer, $5^{\prime}$ - GGC CTCTTGTGCTGCTGGATGGGAACATGGCCA $-3^{\prime}$. The sequences of all constructs were confirmed by restriction digestion and direct sequencing.

Transient transfections and luciferase assays

Transient transfections were performed using Lipofectamine 2000 reagent (Invitrogen) according to the manufacturer's instructions as described before [25]. Briefly, cells were seeded in a 24-well plate for 24 $\mathrm{h}$ before transfection. For each well of cells, $0.8 \mu \mathrm{g}$ of the CD36 reporter construct was cotransfected with $0.02 \mu \mathrm{g}$ of pRL-TK vector that provides constitutive expression of Renilla luciferase serving as an internal control. After treatment with oxLDL, cells were harvested, and luciferase activity was measured using a Perkin-Elmer 1420 multilabel counter (USA) according to the instructions of the dual luciferase reporter assay system (Promega). All transfection experiments were carried out in triplicate.

Chromatin immunoprecipitation (ChIP)

ChIP analysis was performed using the EZ ChIP Kit (Upstate, Charlottesville, VA, USA) according to the manufacturer's protocol as described before [25]. Briefly, formaldehyde was added to the culture medium and incubated for $10 \mathrm{~min}$ at room temperature. Then, glycine was added to stop fixation, and the cells were scraped and collected. Cell pellets were treated with SDS lysis buffer that contained protease inhibitors. Aliquots of cell lysates were sonicated to shear DNA into 0.2- to 1.0-kb fragments, and cellular debris was removed after centrifugation. The resultant chromatin-containing solutions were aliquotted $(100 \mu \mathrm{l})$ and stored at $-80{ }^{\circ} \mathrm{C}$ until use. Chromatin aliquots were precleared with $60 \mu \mathrm{l}$ of $50 \%$ protein $\mathrm{G}$ agarose suspension. Samples were then incubated with anti-Mipu1antibody or normal rabbit IgG (Santa 


\begin{tabular}{|c|c|c|}
\hline Cellular Physiology & Cell Physiol Biochem 2015;37:879-889 & \\
\hline and Biochemistry & $\begin{array}{l}\text { DOI: 10.1159/000430215 } \\
\text { Published online: September 18, } 2015\end{array}$ & $\begin{array}{l}\text { O } 2015 \text { S. Karger AG, Basel } \\
\text { www.karger.com/cpb }\end{array}$ \\
\hline
\end{tabular}

Cruz iotechnology) overnight at $4{ }^{\circ} \mathrm{C}$ with rotation. Immune complexes were mixed with protein $\mathrm{G}$ agarose suspension. Beads were collected by brief centrifugation and the immunocomplexes were eluted by freshly prepared elution buffer. Chromatin was then de-crosslinked for $5 \mathrm{~h}$ at $65^{\circ} \mathrm{C}$. After treatment with proteinase K, DNA was purified with a QiaQuick PCR purification kit (Qiagen) and finally eluted in $50 \mu$ of Tris EDTA.

An aliquot $(2 \mu \mathrm{l})$ of each sample was subjected to PCR analysis using HotStar Taq DNA polymerase (Qiagen) (32 cycles). The two pairs of primers used to amplify the proximal region of the CD36 promoter that contained the MRE were primers that contained the-237 bp to -244 bp Mipu1 binding site, $5^{\prime}$ CCGTTGGTTCTCTGGCCT CTG-3' and 5'-AAAGAAAGAGAAGAAAAAAAGTTAAGGG-3'.

Statistical analyses

The results are expressed as mean \pm SEM. Statistical analyses were performed with the Graphpad Prism V.5 software using the Student's t-test. Significance was taken as $p<0.05$.

\section{Results}

Fig. 1. oxLDL increases the expression of Mipu1. (A,E) Time course of oxLDL-induced Mipu1 mRNA expression levels. oxLDL (75 mg/L) was added for the indicated periods of time. Total RNA was isolated from each sample, and real-time RT-PCR was performed to quantify Mipu1 mRNA expression levels, shown as the relative difference from the control normalized to GAPDH expression levels. (B,F) Concentration-response effect of oxLDL on Mipu1 mRNA expression. RAW264.7 cells were treated as described above and with the indicated concentrations of oxLDL for $24 \mathrm{~h}$. $(\mathrm{C}, \mathrm{G})$ Time course of oxLDL-induced Mipu1 protein expr

A

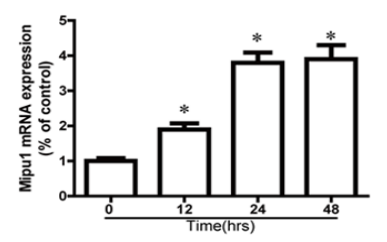

C

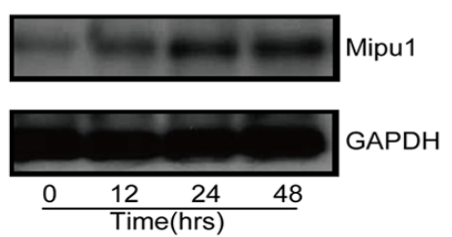

E

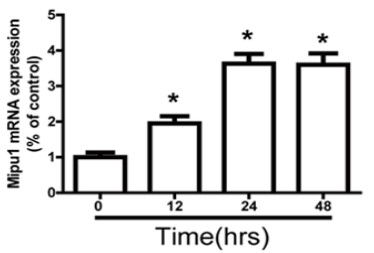

G

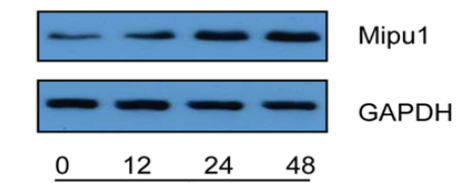

।

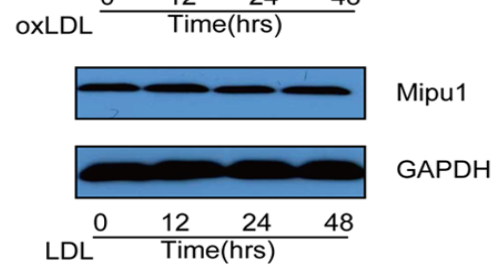

B

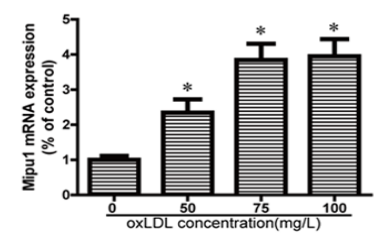

D
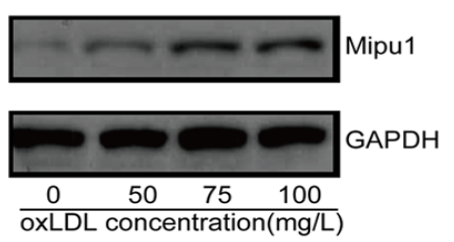

F

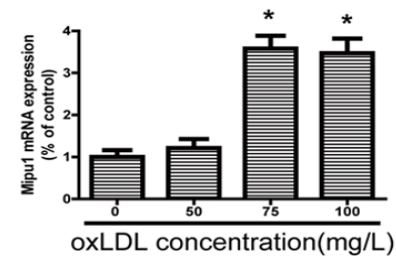

$\mathrm{H}$

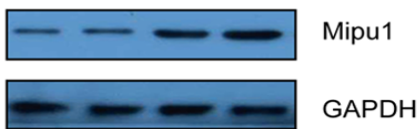

J
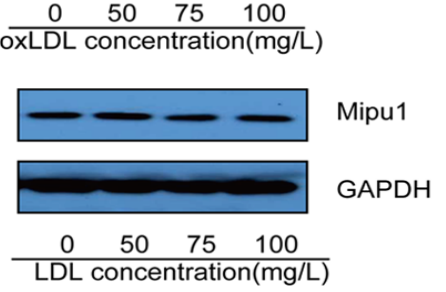

evels. $(\mathrm{D}, \mathrm{H})$ Concentration-response effect of oxLDL on Mipu1 protein expression. All data represent three independent experiments. ${ }^{*} P<0.05$ versus control. A-D, RAW264.7 cells; E-H, THP-1 cells. (I)LDL (75 mg/L) was added for the indicated periods of time in RAW264.7 cells. (J) RAW264.7 cells were treated with the indicated concentrations of LDL for $24 \mathrm{~h}$. All data represent three independent experiments. ${ }^{*} P<0.05$ versus control. 
Fig. 2. oLDL increases the mRNA expression and promoter activity of CD36 in RAW264.7 cells. (A) Time course of oxLDL-induced CD36 mRNA expression levels. oxLDL $(75 \mathrm{mg} / \mathrm{L})$ was added for the indicated periods of time. Total RNA was isolated from each sample, and real-time RT-PCR was performed to quantify CD36 mRNA expression levels, shown as the relative difference from the control normalized to GAPDH expression levels. B Time course of
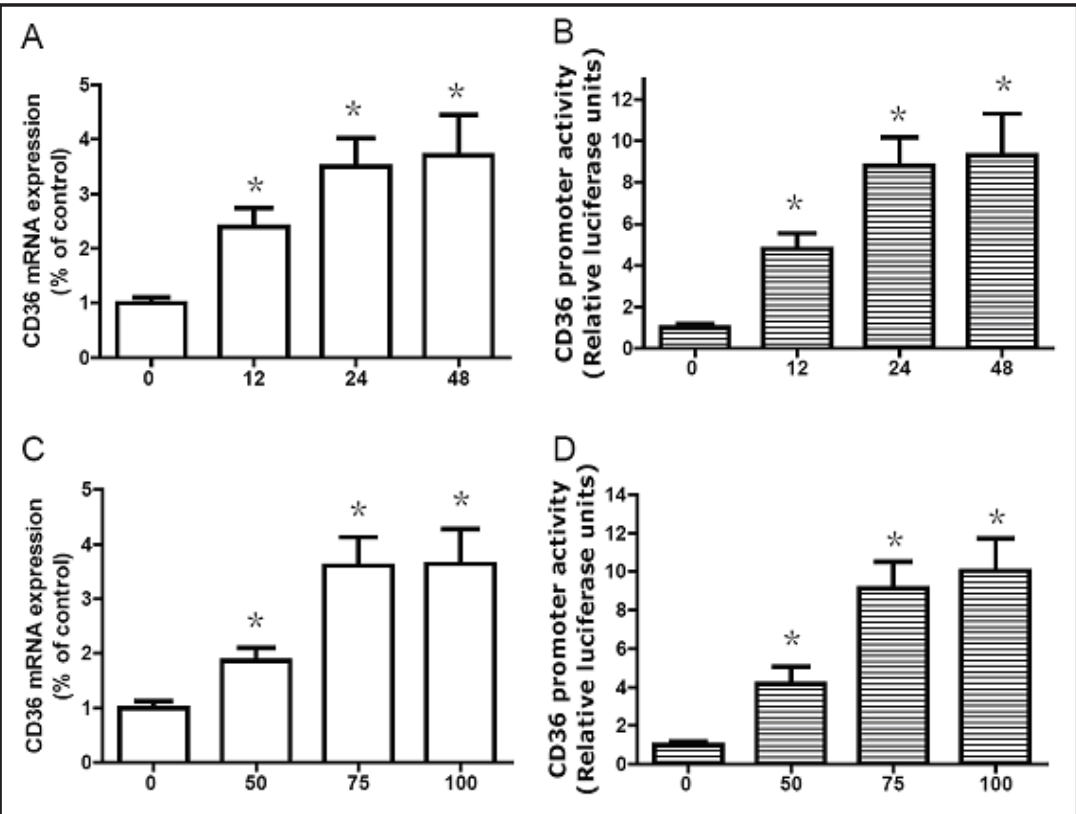
oxLDL-induced CD36 promoter activity. Mouse CD36 promoter region from -1200 to $+299 \mathrm{bp}$ was cloned. RAW264.7 cells were transfected with CD36 promoter report gene, then treated with oxLDL(75 mg/L) for the indicated periods of time and luciferase assays were performed. The reporter activities are shown as the relative luciferase units (RLU) normalized to the pRL-TK vector activity. (D) Concentration-response effect of oxLDL on CD36 promoter activity. All data represent three independent experiments. ${ }^{*} P<0.05$ versus control.

The effect of oxLDL on Mipu1 gene expression

The effect of oxLDL on Mipu1 expression was studied using quantitative real-time RT-PCR and western blot. Treatment of RAW264.7 (Fig. 1A-D) or THP-1(Fig. 1E-H) cells with oxLDL (75 mg/L) for $24 \mathrm{~h}$ resulted in a four-fold increase in Mipu1 mRNA expression compared to controls. Similar increases in Mipu1 protein expression were observed using western blot. The results showed that Mipu1 mRNA and protein expression responsed to oxLDL, but not LDL (Fig. 1 I,J), with a time and concentration-dependent way (Fig. 1).

The effect of oxLDL on CD36 mRNA expression and promoter activity

The effect of oxLDL on CD36 mRNA expression and promoter activity was studied using quantitative real-time RT-PCR and luciferase assays. Cells were incubated with oxLDL for various doses and periods of time. mRNA expression of Mipu1 and CD36 was determined by real-time PCR, and luciferase assay was used to detect CD36 promoter activity. As shown in Fig. 2A, B, RAW264.7 cells were incubated with $75 \mu \mathrm{g} / \mathrm{ml}$ oxLDL for various periods of time ranging from 0 to $48 \mathrm{hs}$. The results showed a sustainable increase of CD36 at both mRNA (Fig. 2A) and promoter activity in a time-dependent manner (Fig. 2B). Moreover, at concentrations of $0,50,75$, and $100 \mu \mathrm{g} / \mathrm{ml}, 24$-hs oxLDL treatment on RAW264.7 cells led to a significant increase in mRNA levels and promoter activity of CD36(Fig. 2C and Fig. 2D).

\section{Identification of a functional MRE in the mouse CD36 promoter}

The functional MRE involved in oxLDL responsiveness of the CD36 promoter was next identified. The mouse CD36 promoter contains two potential MREs, residing between -237 and-244 and between-127 and -134, which were termed as MRE-I and MRE- II , respectively. To identify the functional MRE(s), mutants of the mouse CD36 promoter were constructed by serially deleting the fragment from -1200 to +299 . As shown in Fig. 3B, the deletion from -600 to -230 , containing MRE- II , showed the most drastically increase to oxLDL. To evaluate further the functional significance of MRE- II in the CD36 promoter after oxLDL 
Fig. 3. The mouse CD36 gene promoter is transcriptional target of Mipu1. A, Mouse CD36 promoter region from -1200 to $+299 \mathrm{bp}$ was cloned. RAW264.7 cells were treated with oxLDL for 24 $h$, then luciferase assays were performed. B, Mouse CD36 promoter analysis by series of deletion. C, The mutated sequences of MRE- II (from -1200 to $+299 b p$ ) are presented. The sequence of the Mut-Luc construct was identical to the Wt-Luc construct except for the mutated sequences (GACTTACT). D, Chromatin immunoprecipitation
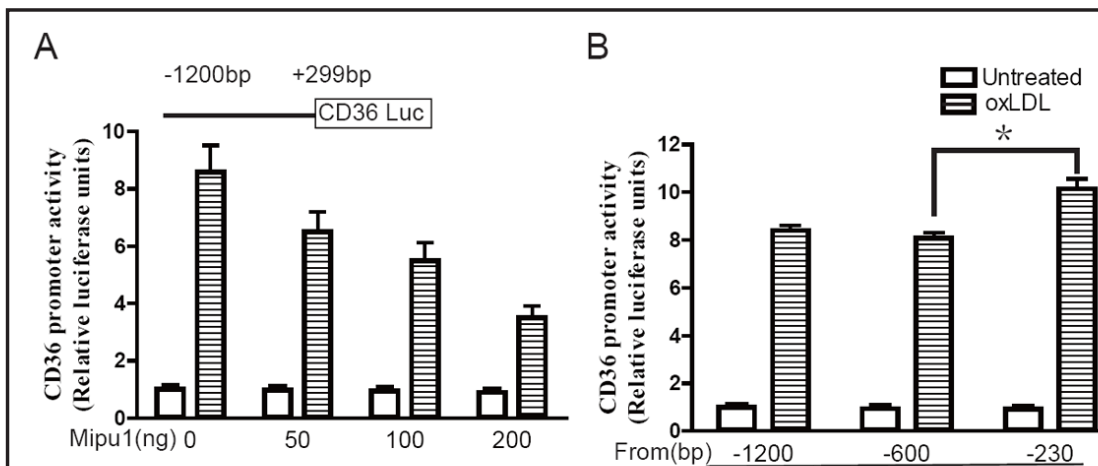

C
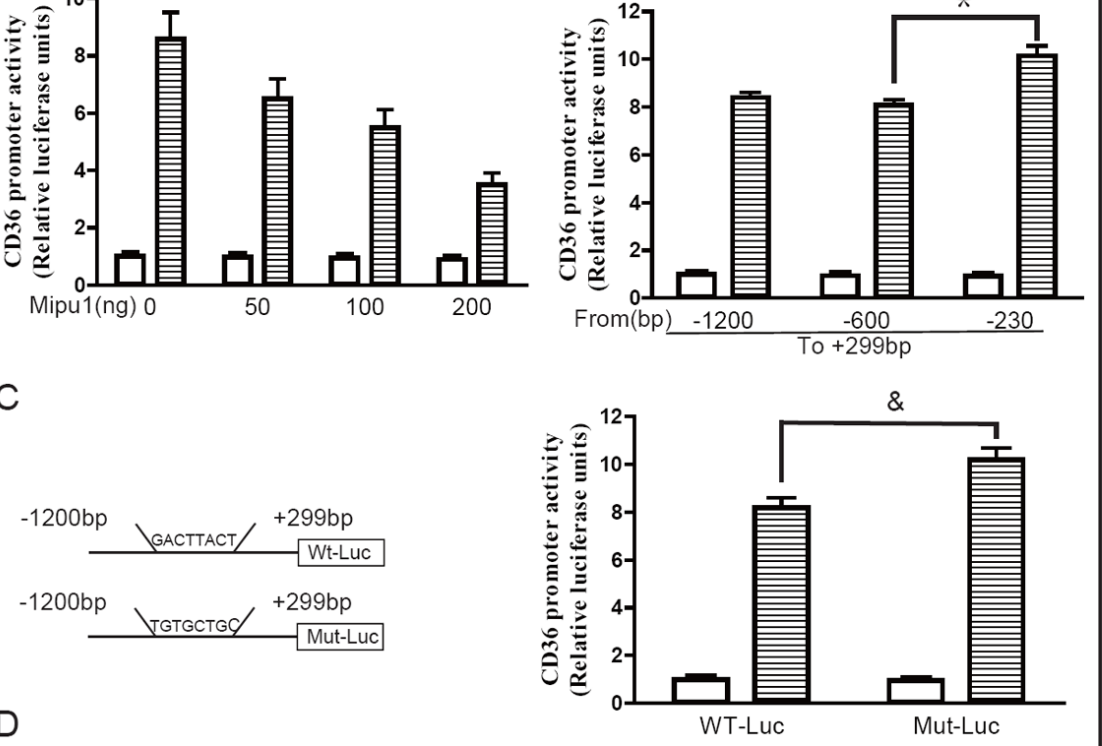

(ChIP) was used to show the recruitment of Mipu1 onto the CD36 promoter. Precipitated DNA fragments were analyzed by qPCR using primers flanking the Mipu1 binding site (ACTTAC) in the CD36 promoter. An isotype-matched immunoglobulin $\mathrm{G}$ was used as a negative control and 1\% input (PCR product of 1/100 of the total isolated DNA used in the ChIP assay) was used as a positive control. ${ }^{*} P<0.05$. All data represent three independent experiments. IgG, immunoglobulin G.

treatment, site-specific mutations were introduced into MRE- II, and oxLDL responsiveness of the mutant construct was determined using transient transfection analysis. Substitutions of four base pairs that flanked MRE- II abolished the oxLDL responsiveness of the mutant construct compared to the wild-type construct (Wt MRE-II) (Fig. 3C). MRE-II is therefore the cis-acting element of the CD36 promoter involved in responses to oxLDL. Direct Mipu1 binding to MRE-II in the CD36 promoter was next determined by measuring occupancy of MRE-II using ChIP assays. oxLDL increased Mipu1 binding to MRE-II of the CD36 promoter (Fig. 3D).

Mipu1 regulated oxLDL-induced lipid accumulation by modulating CD36 expression in RAW264.7 cells

The development of foam cells containing massive amounts of cholesteryl esters (CE) is a hallmark of AS. CD36 is the most important SR which uptakes oxLDL and contributes to the formation of foam cells $[27,28]$. To determine the functional significance of Mipu1 in foam-cell formation, we downregulated expression of endogenous Mipu1 in RAW264.7 cells. HPLC analysis showed that knockdown of Mipu1 has increased cholesteryl esters (CE), total cholesterol (TC) and free cholesterol (FC) levels comparison with control in RAW264.7 cells. 


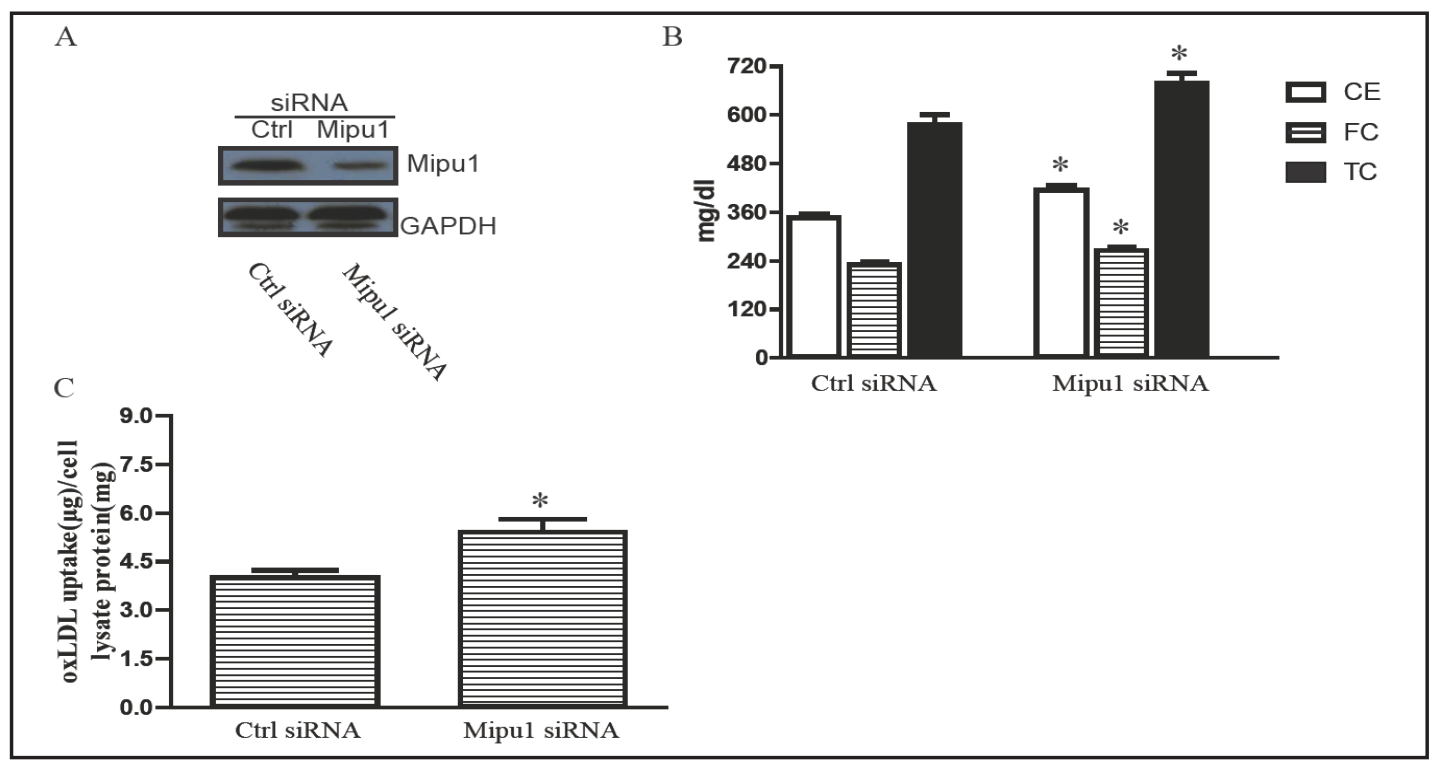

Fig. 4. Mipu1 downregulation increases oxLDL-induced lipid accumulation in RAW264.7 cells. A, protein expression of Mipu1 in RAW264.7 cells transfected with Mipu1 siRNA were analyzed by western blot. B, RAW264.7-Ctrl siRNA and RAW264.7-Mipu1 siRNA cells were treated with $75 \mathrm{mg} / \mathrm{L}$ ox-LDL for $24 \mathrm{~h}$, and the intracellular cholesterol content was measured via HPLC. C, under the same conditions as in (B), cells were incubated with Dil-labeled oxLDL (75 mg/L) for $24 \mathrm{~h}$, and uptake of oxLDL identified by Dil-ox-LDL fluorescence intensity. Data are presented as the mean \pm SEM of at least four independent experiments. ${ }^{*} P<0.05$ vs. pcDNA3.1 group.

Fig. 5. Mipu1 downexpression induced CD36 expression and CD36 promoter activity in the presence of oxLDL. (A) RAW264.7-Ctrl siRNA and RAW264.7-Mipu1 siRNA cells were incubated with $75 \mathrm{mg} /$ $\mathrm{mL}$ oxLDL for $24 \mathrm{~h}$, then protein expression of CD36 was detected by western blot. (B) Mouse CD36 promoter region from -1200 to +299 bp was cloned. RAW264.7-Ctrl siRNA and RAW264.7-Mipu1 siRNA cells were transfected with CD36 promoter report gene, then treated with oxLDL(75 mg/L) for $24 \mathrm{~h}$ and luciferase assays were performed. The reporter activities are shown as the relative luciferase units (RLU) nor-

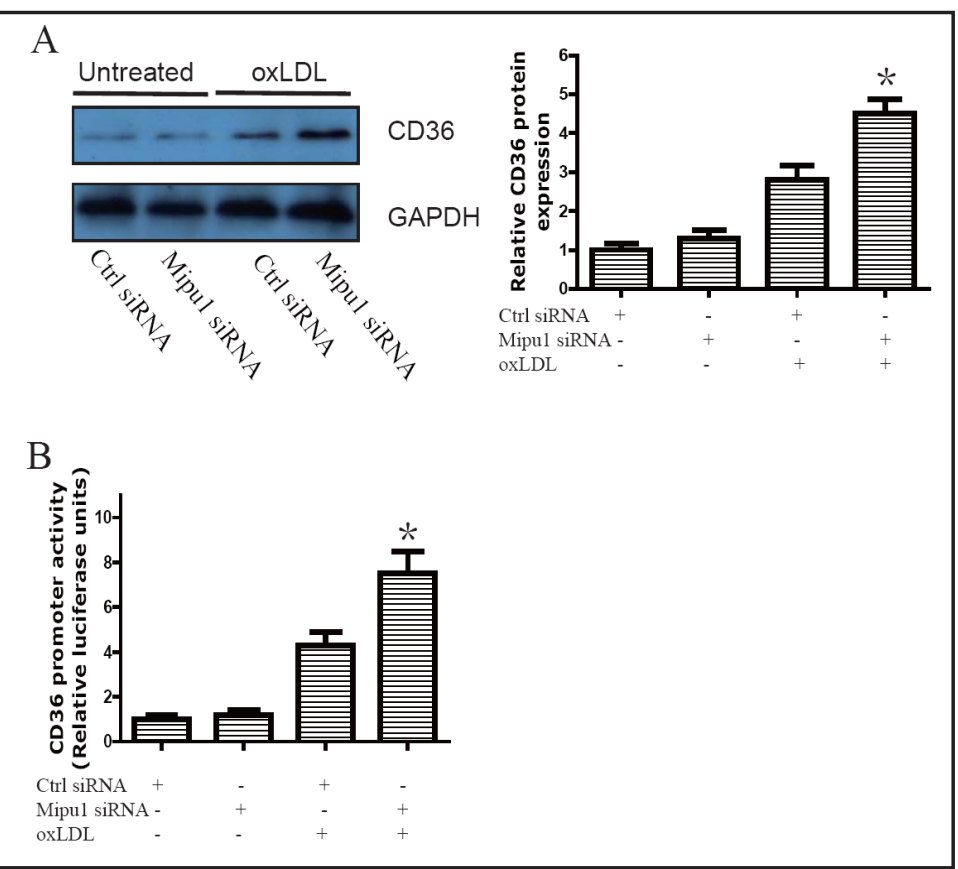
malized to the pRL-TK vector activity. All data represent three independent experiments. ${ }^{*} P<0.05$ versus RAW264.7-Ctrl siRNA cells treated with oxLDL.

Mipu1 deficiency aggravated oxLDL-induced lipid accumulation (Fig. 4). Not surprisingly, an elevated CD36 expression can be detected both in mRNA and protein levels when Mipu1 knockdown in oxLDL treatment cells. Meanwhile, the CD36 promoter activity also has a significant increase in the simultaneous presence of oxLDL and Mipu1 deficiency (Fig. 5).

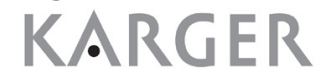




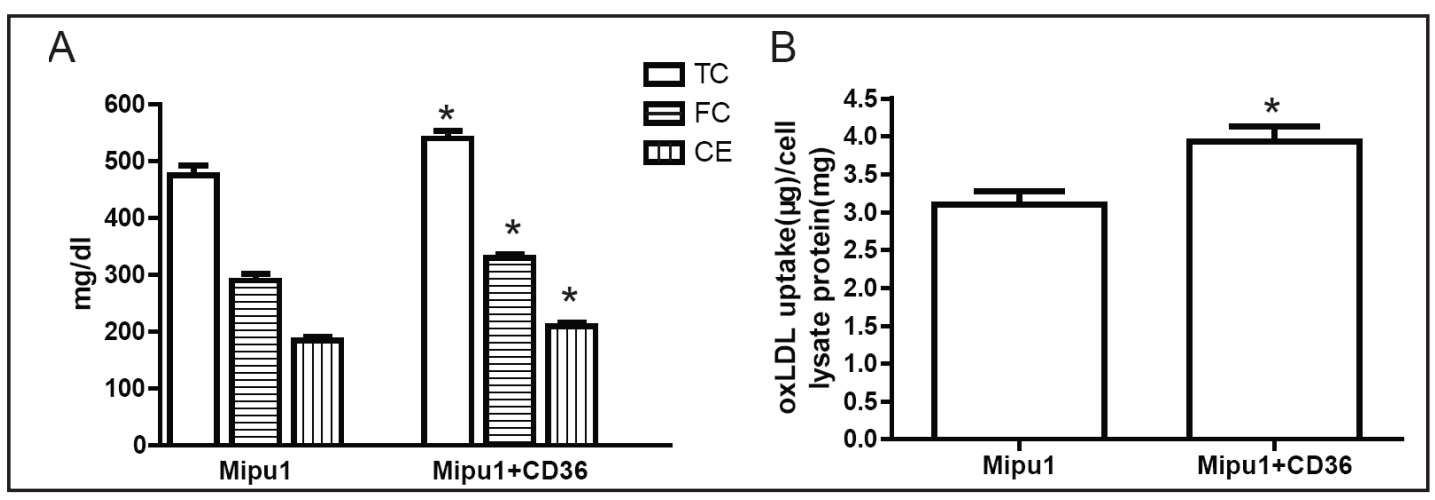

Fig. 6. Overexpression of CD36 rescues lipid accumulation in RAW264.7-Mipu1 cells. A, Intracellular cholesterol content was measured via HPLC after treatment with ox-LDL $(75 \mu \mathrm{g} / \mathrm{ml})$ for $24 \mathrm{~h}$. B, Fluorescence intensity was detected after incubation with Dil-labeled ox-LDL $(75 \mu \mathrm{g} / \mathrm{ml})$ for $24 \mathrm{~h}$. Mipu1:RAW264.7-Mipu1 cells; Mipu1+CD36:RAW264.7-Mipu1 cells were transfected with CD36 plamid. Data are presented as the mean \pm SEM of at least four independent experiments. ${ }^{*} P<0.05$ vs. Mipu1 group.

Overexpression of CD36 reversed reduction of lipid accumulation in RAW264.7-Mipu1 cells

Our recent data indicated that Mipu1 overexpression attenuated oxLDL-induced lipid accumulation[22]. However, its mechanism is not clear. To further conform whether Mipu1 reduces lipid accumulation through CD36, pIRES -CD36 plasmid was transfected to RAW264.7-Mipu1 cells. HPLC analysis showed that overexpression of CD36 increased CE, TC and FC levels (Fig. 6A). We also detected the effect of CD36 overexpression on oxLDL uptake by macrophages. As shown in Fig. 6B, CD36 overexpression also induced uptake of oxLDL in macrophages.

\section{Discussion}

It was also shown that Mipu1 protein was localized to the nucleus of $\mathrm{H} 9 \mathrm{c} 2$ cardiomyocytes and was up-regulated after treatment with $\mathrm{H}_{2} \mathrm{O}_{2}$ [20]. Another observation indicated that over-expression of Mipu1 reduced the growth arrest induced by serum withdrawal in C2C12 myogenic cells [18]. These observations indicated that Mipu1 may play a role in maintaining cell homeostasis and protecting the cells from being injured by I/R or oxidative stress. Foam cell formation is a hallmark of the early stages of AS and plays an important role in plaque progression and instability [29-31]. Increasing evidence has indicated that the foam cells found in the atherosclerotic reaction are macrophages that are derived from blood-borne monocytes or smooth muscle cells. The hallmark of these foam cells is the cholesteryl ester content is over $50 \%$ of the total intracellular cholesterol [32,33]. RAW264.7 macrophages are easy to culture and have strong phagocytic and adhesive abilities, so it has been widely used in studies of the pathways of foam cell formation. In this study, macrophages meet the typical characteristic of foam cells after treatment with $75 \mathrm{mg} / \mathrm{L}$ oxLDL for $24 \mathrm{~h}$. Our primary data indicated that Mipu1 overexpression not only decreased uptake of oxLDL, but also synergistically reduced the oxLDL-induced intracellular cholesterol accumulation and inhibited foam-cell formation, and might be associated with modulation of CD36 expression [22], however the precise mechanism is not clear. In this study, our data showed that oxLDL not only increased Mipu1 expression, but also synergistically induced CD36 mRNA and promoter activity (Fig. 1 and Fig. 2). Increasing evidences suggests that CD36 is an important target for AS treatment [2], together with our recent results [22], we hypothesized that Mipu1 may be decrease oxLDL uptake by modulating CD36 expression and/or activity. Indeed, CD36 overexpression rescues lipid accumulation in RAW264.7-Mipu1 cells upon oxLDL 
treatment (Fig. 3). It suggested that Mipu1 inhibits the oxLDL-induced lipid accumulation in macrophages via downregulating of CD36 expression. It is proposed that there are also other mechanisms in addition to the downregulation of CD36 expression that are responsible for the cholesterol uptake in presence of oxLDL.

We attempted to determine the transcriptional mechanisms of Mipu1 by which oxLDL down-regulated the expression of CD36 gene. We cloned the mouse CD36 promoter and, using the RAW264.7 cells, identified a functional MRE, MRE- II (GACTTACT). In our sequencebased analysis of the mouse CD36 promoter using the MatInspector program, there was two potential MRE (MRE- I :5' - AGCTTAAC-3' and MRE- II : GACTTACT). However, the MRE- I site does not seem to be functional because its presence did not significantly affect the oxLDL responsiveness of the CD36 promoter (Fig. 4B). Deletion of the MRE-II region resulted in significantly increased oxLDL responsiveness of the promoter (Fig. 4B). Mipu1 induced by oxLDL could bind to MRE-II of the mouse CD36 promoter (Fig. 4D). Moreover, nucleotide substitutions in the MRE-II region directly affected oxLDL responsiveness of the CD36 promoter compared to Wt MRE-II (Fig. 4C). These results demonstrated that MRE-II was a functional element for oxLDL- mediated CD36 transcription. A critical functional role for oxLDL-mediated regulation of Mipu1 in the modulation of CD36 expression was further demonstrated in the studies using a siRNA knockdown strategy (Fig. 4). Interestingly, the reduction in Mipu1 expression by siRNA and the subsequent induction of CD36 levels (Fig. 5). However, the Mipu1 over-expression in RAW264.7 cells showed only $50 \%$ reduction in oxLDL-induced CD36 expression (Fig. 3). One possible explanation for this observation is that other transcriptional factors, yet unknown, may add to the net capacity of the cells to mediate CD36 expression during oxLDL stimulation.

For mechanism of oxLDL-induced Mipu1expression, We have domosteand specific binding sites for Sp1-family transcription factors on Mipu1 promoter. We also searched transcription-factor-binding sites on the Mipu1 promoter using MatInspector and found some potential-binding sites of stress-response transcription factors, such as HIF alpha, HSF-1, Elk-1, Egr-1, and the GAGA-binding protein [34]. oxLDL can trigger HIF-1alpha accumulation [35] and induced of tissue factor gene expression mediated by both Egr-1 and Sp1 [36]. Thus, further studies are needed to explore the mechanism of Mipu1 up-regulation during oxLDL exposure.

Putting these results in context with the findings of others, we propose that Mipu1 serves as a key protein in macrophages responding to oxLDL stimulation via down-regulating CD36 expression. Our findings are of relevance for the understanding of Mipu1 that contribute to prevention of atherosclerosis.

\section{Acknowledgements}

This work was supported by grants from the Science and Technology Project of Hunan Province (2014FJ3014), the key Scientific Research Fund of Hunan Provincial Education Department (15A166), the Natural Science Foundation of Hunan Province (2015JJ2118), the National Natural Science Foundation of China (81100212, 81170277 and 81100106), the Ph.D. Programs Foundation of Ministry of Education of China (20114324120004 and 20124324110003), the China Postdoctoral Science Foundation (2012M511383), the Scientific Research Fund of Hunan Provincial Education Department (11C1094 and 11C1095), the Aid Program for Science and Technology Innovative Research Team in Higher Educational Institutions of Hunan Province (2008-244) and the Construct Program of the Key Discipline in Human Province (2011-76).

\section{Disclosure Statement}

There is no conflict of interests regarding the publication of this paper for all the authors. 


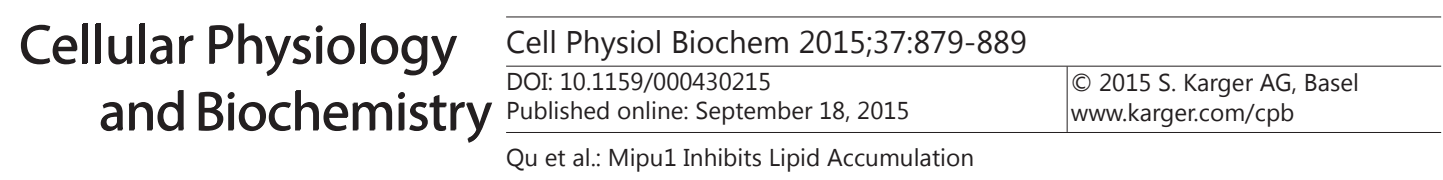

\section{Reference}

1 Go AS, Mozaffarian D, Roger VL, Benjamin EJ, Berry JD, Borden WB, Bravata DM, Dai S, Ford ES, Fox CS, Franco S, Fullerton HJ, Gillespie C, Hailpern SM, Heit JA, Howard VJ, Huffman MD, Kissela BM, Kittner SJ, Lackland DT, Lichtman JH, Lisabeth LD, Magid D, Marcus GM, Marelli A, Matchar DB, McGuire DK, Mohler ER, Moy CS, Mussolino ME, Nichol G, Paynter NP, Schreiner PJ, Sorlie PD, Stein J, Turan TN, Virani SS, Wong ND, Woo D, Turner MB: Executive summary: Heart disease and stroke statistics--2013 update: A report from the american heart association. Circulation 2013;127:143-152.

2 Yu XH, Fu YC, Zhang DW, Yin K, Tang CK: Foam cells in atherosclerosis. Clin Chim Acta 2013;424:245-252.

3 Zhao JF, Ching LC, Huang YC, Chen CY, Chiang AN, Kou YR, Shyue SK, Lee TS: Molecular mechanism of curcumin on the suppression of cholesterol accumulation in macrophage foam cells and atherosclerosis. Mol Nutr Food Res 2012;56:691-701.

4 Yuan Y, Li P, Ye J: Lipid homeostasis and the formation of macrophage-derived foam cells in atherosclerosis. Protein Cell 2012;3:173-181.

5 Goldschmidt-Clermont PJ, Dong C, Seo DM, Velazquez OC: Atherosclerosis, inflammation, genetics, and stem cells: 2012 update. Curr Atheroscler Rep 2012;14:201-210.

6 Yang Y, Lian YT, Huang SY, Yang Y, Cheng LX, Liu K: Gaba and topiramate inhibit the formation of human macrophage-derived foam cells by modulating cholesterol-metabolism-associated molecules. Cell Physiol Biochem 2014;33:1117-1129.

7 Chen K, Febbraio M, Li W, Silverstein RL: A specific cd36-dependent signaling pathway is required for platelet activation by oxidized low-density lipoprotein. Circ Res 2008;102:1512-1519.

8 Liu Y, Geng J, Liu Y, Li Y, Shen J, Xiao X, Sheng L, Yang B, Cheng C, Li W: Beta3-adrenoceptor mediates metabolic protein remodeling in a rabbit model of tachypacing-induced atrial fibrillation. Cell Physiol Biochem 2013;32:1631-1642.

9 Rahaman SO, Lennon DJ, Febbraio M, Podrez EA, Hazen SL, Silverstein RL: A cd36-dependent signaling cascade is necessary for macrophage foam cell formation. Cell Metab 2006;4:211-221.

10 Silverstein RL: Inflammation, atherosclerosis, and arterial thrombosis: Role of the scavenger receptor cd36. Cleve Clin J Med 2009;76:S27-30.

11 Febbraio M, Abumrad NA, Hajjar DP, Sharma K, Cheng W, Pearce SF, Silverstein RL: A null mutation in murine cd36 reveals an important role in fatty acid and lipoprotein metabolism. J Biol Chem 1999;274:19055-19062.

12 Kuchibhotla S, Vanegas D, Kennedy DJ, Guy E, Nimako G, Morton RE, Febbraio M: Absence of cd36 protects against atherosclerosis in apoe knock-out mice with no additional protection provided by absence of scavenger receptor a i/ii. Cardiovasc Res 2008;78:185-196.

13 Reeves RS: Great (but realistic) expectations: What ada can (and can't) do for you. J Am Diet Assoc 2005;105:1049.

14 Yao S, Miao C, Tian H, Sang H, Yang N, Jiao P, Han J, Zong C, Qin S: Endoplasmic reticulum stress promotes macrophage-derived foam cell formation by up-regulating cluster of differentiation 36 (cd36) expression. J Biol Chem 2014;289:4032-4042.

15 Chavez-Sanchez L, Garza-Reyes MG, Espinosa-Luna JE, Chavez-Rueda K, Legorreta-Haquet MV, BlancoFavela F: The role of tlr2, tlr4 and cd36 in macrophage activation and foam cell formation in response to oxldl in humans. Hum Immunol 2014;75:322-329.

16 Badrnya S, Schrottmaier WC, Kral JB, Yaiw KC, Volf I, Schabbauer G, Soderberg-Naucler C, Assinger A: Platelets mediate oxidized low-density lipoprotein-induced monocyte extravasation and foam cell formation. Arterioscler Thromb Vasc Biol 2014;34:571-580.

17 Yuan C, Zhang H, Liu Y, Wang Q, Xiao X: Cloning and characterization of a new gene mip1 up-regulated during myocardial ischemia-reperfusion. Prog Biochem Biophys 2004;31:231-236.

18 Jiang L, Tang D, Wang K, Zhang H, Yuan C, Duan D, Xiao X: Functional analysis of a novel krab/c2h2 zinc finger protein mipu1. Biochem Biophys Res Commun 2007;356:829-835.

19 Han D, Zhang C, Fan WJ, Pan WJ, Feng DM, Qu SL, Jiang ZS: Myocardial ischemic preconditioning upregulated protein 1(mipu1):Zinc finger protein 667 - a multifunctional krab/c2h2 zinc finger protein. Braz J Med Biol Res 2015;48:1-5.

20 Wang G, Zuo X, Liu J, Jiang L, Liu Y, Zheng Y, Zhang B, Xiao X: Expression of mipu1 in response to myocardial infarction in rats. Int J Mol Sci 2009;10:492-506. 


\section{Cellular Physiology Cell Physiol Biochem 2015;37:879-889 \begin{tabular}{l|l|l} 
DOI: 10.1159/000430215 & (C) 2015 S. Karger AG, Basel
\end{tabular} www.karger.com/cpb \\ Qu et al.: Mipu1 Inhibits Lipid Accumulation}

21 Wang K, Lei J, Zou J, Xiao H, Chen A, Liu X, Liu Y, Jiang L, Xiao Z, Xiao X: Mipu1, a novel direct target gene, is involved in hypoxia inducible factor 1-mediated cytoprotection. PLoS One 2013;8:e82827.

22 Qu SL, Fan WJ, Zhang C, Guo F, Han D, Pan WJ, Li W, Feng DM, Jiang ZS: Mipu1 overexpression protects macrophages from oxldl-induced foam cell formation and cell apoptosis. DNA and cell biology 2014;33:839-846.

23 Zhu HL, Wei X, Qu SL, Zhang C, Zuo XX, Feng YS, Luo Q, Chen GW, Liu MD, Jiang L, Xiao XZ, Wang KK: Ischemic postconditioning protects cardiomyocytes against ischemia/reperfusion injury by inducing mip2. Exp Mol Med 2011;43:437-445.

24 Jiang L, Zhang B, Wang G, Wang K, Xiao X: Expression, purification and characterization of rat zinc finger protein mipu1 in escherichia coli. Mol Cell Biochem 2009;328:137-144.

25 Qu S, Zhu H, Wei X, Zhang C, Jiang L, Liu Y, Luo Q, Xiao X: Oxidative stress-mediated up-regulation of myocardial ischemic preconditioning up-regulated protein 1 gene expression in h9c2 cardiomyocytes is regulated by cyclic amp-response element binding protein. Free Radic Biol Med 2010;49:580-586.

26 Ma X, Hu YW, Mo ZC, Li XX, Liu XH, Xiao J, Yin WD, Liao DF, Tang CK: No-1886 up-regulates niemann-pick c1 protein (npc1) expression through liver x receptor alpha signaling pathway in thp-1 macrophagederived foam cells. Cardiovasc Drugs Ther 2009;23:199-206.

27 Liu HY, Cui HB, Chen XM, Chen XY, Wang SH, Du WP, Zhou HL, Zhao RC, Zhou Y, Liu YH, Cui CC, Huang C: Imbalanced response of atp-binding cassette transporter a1 and cd36 expression to increased oxidized low-density lipoprotein loading contributes to the development of thp-1 derived foam cells. J Biochem 2014;155:35-42.

28 Rodrigue-Way A, Caron V, Bilodeau S, Keil S, Hassan M, Levy E, Mitchell GA, Tremblay A: Scavenger receptor cd36 mediates inhibition of cholesterol synthesis via activation of the ppargamma/pgc-1alpha pathway and insig1/2 expression in hepatocytes. FASEB J 2014;28:1910-1923.

29 Choudhury RP, Lee JM, Greaves DR: Mechanisms of disease: Macrophage-derived foam cells emerging as therapeutic targets in atherosclerosis. Nat Clin Pract Cardiovasc Med 2005;2:309-315.

30 Iwata H, Aikawa M: Liver-artery interactions via the plasminogen-cd36 axis in macrophage foam cell formation: New evidence for the role of remote organ crosstalk in atherosclerosis. Circulation 2013;127:1173-1176.

31 Sledzinski T, Korczynska J, Goyke E, Stefaniak T, Proczko-Markuszewska M, Kaska L, Swierczynski J: Association between cytosolic glycerol 3-phosphate dehydrogenase gene expression in human subcutaneous adipose tissue and bmi. Cell Physiol Biochem 2013;32:300-309.

32 Fogelman AM, Shechter I, Seager J, Hokom M, Child JS, Edwards PA: Malondialdehyde alteration of low density lipoproteins leads to cholesteryl ester accumulation in human monocyte-macrophages. Proc Natl Acad Sci U S A 1980;77:2214-2218.

33 Boyle JJ, Johns M, Kampfer T, Nguyen AT, Game L, Schaer DJ, Mason JC, Haskard DO: Activating transcription factor 1 directs mhem atheroprotective macrophages through coordinated iron handling and foam cell protection. Circ Res 2012;110:20-33.

34 Lv B, Tang Y, Li X, Wang G, Yuan C, Liu Y, Jiang L, Xiao X: Identification and characterization of the minimal promoter of mipu1: The role of gc boxes in the regulation of basal transcription. Acta Biochim Biophys Sin (Shanghai) 2009;41:309-315.

35 Shatrov VA, Sumbayev VV, Zhou J, Brune B: Oxidized low-density lipoprotein (oxldl) triggers hypoxia-inducible factor-1alpha (hif-1alpha) accumulation via redox-dependent mechanisms. Blood 2003;101:4847-4849.

36 Cui MZ, Penn MS, Chisolm GM: Native and oxidized low density lipoprotein induction of tissue factor gene expression in smooth muscle cells is mediated by both egr-1 and sp1. J Biol Chem 1999;274:32795-32802. 